not seem to exist among the Germans. After wintering in the south they mostly go stolidly home, as a matter of course, and often remain sweltering during the dog-days at some watering-place on the Rhine or elsewhere. There they imbibe quantities of mineral waters in the midst of tropical heat, vainly hoping thereby to cure a vital cachexia, only to be arrested or cured by carrying out all the laws of physiology and hygiene, and that to their extreme development and limit.

\section{RECOLLECTIONS OF THE MEDICAL SCHOOL OF BERLIN.}

By H. ROSBOROUGH SWANZY, M.B. Dub.,

Surgeon to the National Eye and Ear Hospital; Ophthalmic Surgeon to the Adelaide Hospital; late Assistant to the late Professor von Graefe, Berlin; etc.

\section{II.}

THERE is one course given at Berlin which in itself would more than amply repay a visit, and in praise of which too much could not be said ; namely, von Langenbeck's Operative Course. He gives two such in the year: one during the Easter recess, from 8 A.M. to IO A.M.; the other in the Summer Session, from 6 A. M. to 8 A.M., several times a week. I never knew von Langenbeck to be five minutes late in commencing. The course is held in the post mortem room of the Pathological Institution, and the Professor walks down thither in the morning from his house smoking a cigar. There are usually three or four subjects to be operated upon by fifteen or twenty students; this being but half the class, while the other half come on the alternate days. Langenbeck, however, frequently confers upon foreigners the privilege of attending with each section. A short lecture is first given on some particular operation, in which the professor sets forth the views of others as well as his own, mentioning the cases to which he thinks the operation most applicable, the degree of success which has attended his performance of it, etc.; and then, if it be one of difficulty-suppose an excision of the knee-he performs it partially or altogether before the class. If, then, there should be three subjects, five students are set to work at the remaining knee-joints, while Langenbeck himself directs and assists them : and, indeed, he appears to be ubiquitous, at everyone's elbow, ready and willing to answer every question satisfactorily. Then another operation is described, and five other students get their turn; and in this way the two hours pass like a dream. At last the professor lights another cigar, and, bowing to the classes, goes off to attend to his house-business (for in Berlin the medical men have two hours at home for their private patients ; one at eight or nine in the morning-and this is the most frequented one-the other at three or four in the afternoon). During this course each student will have done nearly every operation in surgery (including that for cleft palate) two or three times. I believe this course to be quite unique, for where else will be found a surgeon who is covered with honours of every kind, who has been through the hard work of many campaigns, and who, with a world-wide reputation, will still deign to teach students the use of the knife on the dead subject? And yet it happens that the only such surgeon who thinks this not beneath his dignity is one of the best, if not the very best, of living operators.

In papers with a title such as these bear, the name of one, now no more, but with whom the writer had the high honour of being more closely connected than with any of the other Berlin professors, may not be passed over in silence. It is not intended, however, to indulge in a general panegyric upon Albrecht von Graefe. The readers of this JOURNAL have had opportunities, not only in its pages, but elsewhere, of learning what a great and what a good man he was. I would only touch upon the great love he had for his profession, which impelled him to almost superhuman exertions, and which, doubtless, thus hastened his early death. It was von Graefe's wont to visit each one of his hos. pital-patients twice a day-forenoon and evening. His private patients occupied fifty separate rooms, and the poor patients had fifty or sixty beds arranged in wards. The poor and the rich received equal care from Graefe. I have often known him, when circumstances prevented his making his evening visit at an early hour, instead of omitting it altogether, go his rounds long after midnight. He pursued the study of any mode of treatment, which he might happen to investigate, with the greatest regularity and precision. Thus, when engaged with the strabismus operation, he made notes of over eight hundred cases on which he had operated from which to draw his deductions; and some months before his death he had completed the notes of a thousand cases of cataract-extraction performed by his own method. Von Graefe's clinical lectures could not be excelled for clearness and for power of language. He was very fond of lecturing, and continued to lecture when he had to be carried from his carriage to the lecture-theatre. He had preeminently the power of inspiring his pupils with that love, mingled with respect, which appears to be peculiar to the relation of teacher with pupil. But von Graefe died ; and where shall we find one to take his place? Other Bismarcks and other Moltkes might be found, but not another von Graefe.

The vacant chair of ophthalmology in Berlin has been lately filled by the appointment of Professor Schweigger, formerly one of von Graefe's assistants. He has already made a high reputation as an original in vestigator, and he has had great experience in teaching. He will have the direction-thanks to the exertions of his renowned predecessor-of an ophthalmic department in the Charité, containing eighty beds. Red tape has great sway in Berlin, and with it von Graefe had long to contend before he obtained possession of this department in the public hospital, the arrangements having been completed only about a year previously to his death. Until then, he had been in the habit of lecturing in his own private hospital ; but, knowing that this must collapse when he himself went, he was anxious, for the sake of his loved speciality, to provide some hospital appointment to be in connexion with the chair which he occupied.

In 1848 , in consequence of the active part which he took in the political struggles of the time, Virchow was obliged to leave Prussia and take refuge in Würzburg. He lived there for some years as professor in the University, and during this time made many of those researches to which he owes his fame. The Prussian Government, then wishing to appoint the best man to their chair of pathology in Berlin, offered it to Virchow, notwithstanding his unchanged political feelings. $\mathrm{He}$, however, only accepted the honour upon certain conditions, among which was one, that the Government should build for him a pathological institution according to a plan which he specified himself. This and his other demands were acquiesced in; and so Virchow was regained to the Berlin school in a way highly creditable to the Prussian Government, and Berlin has become the fountain.head of all the most important advances made in pathology of late years. The Pathological Institution is situated in the grounds of the Charité, but is not contiguous with the hospital-buildings. It contains two large lecture-rooms, a post mortem room, a pathological laboratory, a laboratory for physiological chemistry (of which more hereafter), private rooms for the professor and his assistants, etc.

\section{FURTHER OBSERVATIONS ON THE TRUE NATURE OF THE SO-CALLED SKIN-GRAFTING.}

\author{
By DAVID PAGE, M.D., \\ Late President of the Royal Medical Society of Edinburgh.
}

IN December last, I wrote an account of my experiments on skin-grafting in the BRITISH MEDICAL JOURNAL, and showed at that time that the physiological changes involved in the growth of the graft, as well as the nature of the graft itself, were quite different from those previously supposed. Indeed, so far as I am aware, my communication, embracing, as it did, the result of microscopic investigation into the subject, was the first in which the true explanation was given of what really constitutes skin-grafting. The conclusion at which I arrived was that, when a piece of the integument is removed from a part of the body, and placed upon the surface of an ulcer showing a disposition to heal, there was no transplantation of cutis, but of cuticle, the deeper layer of which, or rete mucosum, formed the essential portion for subsequent development and growth; and the young newly formed cells of this layer served as the basis for the production of cicatrix. Further, I found that the artificially induced cicatrix, and that which was spontaneously projected from the margin of the ulcer, were identical in structure, and equally possessing the same low vitality and tendency to destruction, from causes that could not affect the normal integument. These results proved satisfactorily that the rete mucosum or stratum Malpighii was the part immediately concerned in the process : and that a graft, to be successful, need consist of this layer only. I held, therefore, the view that it is not a transplantation of skin, but of epithelium; not skin-grafting, but epithelium-grafting.

The numerous clinical observations that have appeared in the medical journals since May of last year, when Mr. Pollock, of St. George's Hospital, introduced the process of M. Reverdin into England, show, by their discrepant statements, that much misunderstanding exists as to the true nature of the changes observed. In several instances, the graft has been supposed to disappear for a time, and to reappear when growth sets in. This phenomenon I have elsewhere explained to arise from the simple fact that, after the desquamation of the upper and 
horny cells of the transplanted epidermis, which always occurs, the young layer of rete mucosum left adherent to the granulations is transparent, and transmits the vascular appearance of the subjacent textures, in proportion to the thickness of that layer.

It has been supposed, also, that the papillary layer of the cutis constitutes the essential portion of the graft; and that while, on the one hand, too deep an incision into the subcutaneous areolar texture was detrimental to the life of the graft, too thin section, on the other, was equally to be avoided, as it would not embrace the papillary layer.

It is interesting to remark, that my views as to the epidermic nature of the graft were corroborated by the clinical results obtained by Dr. David Fiddes of Aberdeen, an account of which appeared in the Lancet for December 17 th, simultaneously with my own communication in the BRITISH Medical Journal.

Dr. Fiddes used in his cases scrapings of epidermic scales simply; which, being placed upon ulcerated surfaces, were followed by the results of ordinary skin-grafting. And in the article on this subject by Dr. George Macleod, Professor of Surgery in the Glasgow University, in the BRITISII MEDICAL JoukNal for April ist, my views as to the value of the rete mucosum in the process are supported by the in ferences drawn by him from his own experiments. He states that "the most reliable results were got from the employment of such a thickness of skin as might be supposed to include the stratum Malpighii, with such a thin section of the corium as served to give it consistence. If a deeper layer were taken, it rarely succeeded, and the use of a less deep part has been already alluded to. That the succeeding growth is due to the cells of the rete mucosum, appears probable. An experiment, alluded to further on, in which the fluid from a blistered surface was used, would point in that direction."

Dr. Macleod failed, as others have done, to obtain very satisfactory results from mere epidermic scales scraped off the surface, as proposed by Dr. Fiddes; and this I consider simply owing to the fact that the uppermost layers of the epidermis consist of cells that are being cast off as effete, and which have undergone chemical and physical changes, rendering them less certain than the newly formed and soft cells of the deeper layers. The same reasoning applies to the success of the fluic of a blister as a substitute for the epithelial graft.

The advantages sought for in skin-grafting are threefold, viz.:-1. Kapidity of cicatrisation; 2. Formation of an elastic and durable cicatrix; 3. Prevention of excessive contraction of surrounding textures, and subsequent deformity.

With regard to the first of these, it is necessary that the ulcer slould be in a perfectly healthy and healing condition, as evinced by the vas. cularity of its edges and vigour of the granulations on its surface. Hence, the weak and indolent, and callous ulcer, must first undergo the usual means of treatment to bring them into this state. In every case where a graft has been transplanted upon an unhcalthy or weak ulcer, the result has been failure.

The formation of a cicatrix of greater durability and elasticity than that spontaneously formed, is an advantage which has beell misconceived, and cannot, I think, be actually attained. To replace effectually the lost integument over a broken surface, nothing short of a true plastic operation would avail, such as the Taliacotian and other modes of restoring defects of the nose and lips, wherein a flap embracing the entire thickness of the cutis vera, with its vascular supply, is only partially raised and removed. One thing must be borne in mind in estimating the value of a new formation such as a cicatrix; and that is, that it is the result of rapid cell-development and growth, the final effort on the part of living textures to close over a breach of surface that has contracted to the utmust of the laxity of neighbouring parts. Now, it happens that both the cicatrices formed on an ulcer healed by the assistance of skin-grafting are identical, and equally devoid of any approach in quality or structure to true skin. The fibro-vascular or deep layer of the cutis, with the hairfollicles, sebaceous, and sweat-glands, if destroyed, cannot be re. generated; but the papillary layer, excepting those papillse of special sense containing the terminal twigs of the sensory nerves, is probably represented in the cicatrix, although it is also true that the latter never attains the same degree of vascularity, and, as a consequence, is of much lower vitality, as shown in the manner in which old cicatrices give way under cachectic states of the system.

As for the prevention of deformity and excessive contraction of neighbouring parts, this must depend upon the original extent of the ulcer and the position in which it occurs; the less good can be effected by skin-graft. ing in this respect in proportion to the amount of tissue destroyed and laxity of the textures around. Take, for example, a burn of the soft parts; it is well known that deep-seated contraction, leading often to irremediable deformity, goes on for some time after the surface has cicatrised; and how mere rapidity, in the latter respect, effected by the adventitious aid of skin-grafting, could obviate these disastrous results, I am at a loss to comprehend. The only advantages, then, of skin -grafing, I must contend to be acceleration of cicatricial growth.

The method of performing the operation adopted by myself is as follows. The most convenient source for the grafis is the skin over the biceps muscle of the arm. This should be gently pinched up by dressing forceps, and then cut off by a stroke of the scissors. The thickness of the cuticle varies in different parts of the body; but, as I hold it essential not only to avoid the subcutaneous textures, but the cutis itsclf, the graft should be removed without any bleeding, if possible-an occurrence which would show that the papillary layer of the cutis, at any rate, had been reached. The sisc of the clliptical piece of cuticle thus removed, should not exceed a quarter of an inch in diameter. The graft is then simply placed upon the surface of the granulations, which it is quite unnecessary to irritate or disturb in any way; and the site chosen should be that where new growth is most desirable. To retain the graft in position, I have used strips of isinglass plaster placed over the surface of the ulcer, and carried partly around the limb. The ordinary dressings may then be applied, and the parts treated in the ordinary way, with systematic bandaging and rest. The progress of the graft may be observed three or four days later, carefully raising the strip of plaster; and in a period varying from that time to a week or so, growth begins. The superficial and older layer of the epidermis has then deecyumated, and will be found lying loose on the surface, while the decp layer of the rete mucosum is left adherent to the granulations, forning a delicate pellicle of a bluish tint. Henceforward, from day to day, as the dressings of the ulcer are renewed, and the progress of the graft seen, its area grows larger and larger by cell-development at the periphery, probably, too, accompanied by coincident increase of growth from the margin of the ulcer, which seems to receive a fresh stimulus from the presence of the graft. Ultimately, the surface will close over, and present the ordinary appearance of a cicatrix. Why transplanted epithelium should lead to the development of its elements, while the granulations themselves appear to be incapable of setting up similar points of cicatrisation spontaneously over the surface, and growth, under ordinary circumstances, only proceeds from the margins, is difficult to understand. Nevertheless, it is a well ascertained fact. Nor does the transplanted epithelium afford a mere point of attachment for such a spontaneous formation; as experiments with pieces of India-rubber and sheepskin, substituted for'skin-grafts, showed that these only acted as foreign matters, causing destruction of the granulations on which they lay.

\section{PROFESSOR FLOWER'S HUNTERIAN LECTURES ON THE TEETH AND ALLIED ORGANS IN THE MAMMALIA.}

\section{Delivered at the Royal Collige of Surgions of England.}

\section{LECTURE XIV. - Monda $y^{2}$ Marci $20 t h$.}

THE Ungulata form a large group, containing, besides the existing forms, many extinct species. They are nearly all purely vegetable feeders; a few are omnivorous. They are divided into two sections or suborders-the Artiodactyles, having an even number of toes on each foot; and the Perissodactyles, having an odd number. These two suborders differ in their teeth and in other particulars.

Of the Perissodactyles, only three cxisting types are known-viz., the Horse and its allies; the Rhinoceros; and the Tapir. These agree one with the other in many points, including the teeth; and their affnities are shown still more distinctly by the study of extinct forms.

Numerous remains of animals, varying in size from the common Horse to the Pig, have been found $i$ in the eocene deposits of the Paris basin. These were arranged by Cuvier under the name of Palreotherium. In general structure, the animals probably resembled the Tapir, perhaps being allied to the Rhinoccros. The teeth were forty-four in number, as is very common among the extinct Ungulata; the formula being $i \frac{3}{3}, c \frac{1}{1}, p \frac{4}{4}, m \frac{3}{3}=44$. In the Palicotherium, the incisors and canines were of moderate size ; next to the canines was a space; beyond this was a row of molar teeth similar in character to each other, the first and second, however, being rather smaller than the others. There was no marked distinction between the premolars and the true molars. The crowns were square and short. In the upper molars, clefts or sinuses ran into the dentine from the outer and inner surfaces, forming sulci, which became gradually obliterated as the tooth wore down, leaving patterns of various forms. In the lower molars, there were two crescentic ridges, with the hollows turned towards each other. 